\title{
Lessons learned from mice deficient in lectin complement pathway molecules
}

Ninette Genster $^{\mathrm{a}^{*}}$, Minoru Takahashi ${ }^{\mathrm{b}^{*}}$, Hideharu Sekine ${ }^{\mathrm{b}}$, Yuichi Endo ${ }^{\mathrm{c}}$, Peter Garred ${ }^{\mathrm{a}}$ and Teizo Fujita $^{\mathrm{d}}$

${ }^{a}$ Laboratory of Molecular Medicine, Department of Clinical Immunology, section 7631

Rigshospitalet, Faculty of Health and Medical Sciences, University of Copenhagen, Denmark

${ }^{\mathrm{b}}$ Department of Immunology, Fukushima Medical University School of Medicine, Fukushima, Japan

${ }^{\mathrm{c}}$ Radioisotope Center, Fukushima Medical University School of Medicine, Fukushima, Japan

${ }^{\mathrm{d}}$ Fukushima General Hygiene Institute, Fukushima, Japan

*These authors contributed equally and should be regarded as joint first authors.

Running head: lectin complement pathway

Keywords: Deficiency, complement, knockout mice, lectin pathway, alternative pathway, MASP, ficolin, mannose-binding lectin, infection, inflammation, development defects

Address of correspondence

Dr. Peter Garred

Laboratory of Molecular Medicine, Department of Clinical Immunology, Sect 7631

Rigshospitalet, Blegdamsvej 9, 2100 Copenhagen O, DENMARK

E-mail: garred@post5.tele.dk, telephone: +45 35457637, telefax: +45 35398766 


\begin{abstract}
The lectin pathway of the complement system is initiated when the pattern-recognition molecules, mannose-binding lectin (MBL), ficolins or collectin-11, bind to invading pathogens or damaged host cells. This leads to activation of $\mathrm{MBL} /$ ficolin/collectin-11 associated serine proteases (MASPs), which in turn activate downstream complement components, ultimately leading to elimination of the pathogen. Mice deficient in the key molecules of lectin pathway of complement have been generated in order to build knowledge of the molecular mechanisms of the lectin pathway in health and disease. Despite differences in the genetic arrangements of murine and human orthologues of lectin pathway molecules, the knockout mice have proven to be valuable models to explore the effect of deficiency states in humans. In addition, new insight and unexpected findings on the diverse roles of lectin pathway molecules in complement activation, pathogen infection, coagulation, host tissue injury and developmental biology have been revealed by in vivo investigations. This review provides an overview of the mice deficient in lectin pathway molecules and highlights some of the most important findings that have resulted from studies of these.
\end{abstract}




\section{Introduction}

The complement system is a part of the innate immune system, responsible for initiation of inflammation and elimination of invading pathogens or altered host cells. Three pathways initiate the complement cascade; the classical, alternative and lectin pathways. All three pathways fuse at formation of the $\mathrm{C} 3$ convertase and cleavage of $\mathrm{C} 3$ into $\mathrm{C} 3 \mathrm{a}$ and $\mathrm{C} 3 \mathrm{~b}$, followed by the formation of the $\mathrm{C} 5$ convertase and cleavage of $\mathrm{C} 5$ into $\mathrm{C} 5 \mathrm{a}$ and $\mathrm{C} 5 \mathrm{~b}$. C5b can interact with $\mathrm{C} 6, \mathrm{C} 7, \mathrm{C} 8$ and multiple C9 units to form the terminal complement complex C5b-9. This cascade of events leads to the formation of cleavage products that function in opsonization, cell lysis and generation of the inflammatory response. The classical pathway is initiated by $\mathrm{C} 1 \mathrm{q}$ binding to antibody bearing immune complexes to initiate the activation of the associated serine proteases $\mathrm{C} 1 \mathrm{r}$ and $\mathrm{C} 1 \mathrm{~s}$, resulting in $\mathrm{C} 4$ and $\mathrm{C} 2$ cleavage and generation of the $\mathrm{C} 3$ convertase. The alternative pathway is activated by spontaneous hydrolysis of $\mathrm{C} 3\left(\mathrm{C} 3\left(\mathrm{H}_{2} \mathrm{O}\right)\right)$. This pathway also functions as an amplification loop for the cleavage of $\mathrm{C} 3$ initially triggered by other mechanisms. $\mathrm{C} 3\left(\mathrm{H}_{2} \mathrm{O}\right)$ or $\mathrm{C} 3 \mathrm{~b}$ bound to target surfaces, i.e. foreign cells, are bound by factor B (FB). Additionally, but still not completely resolved, properdin the positive regulator of alternative pathway activation, may in some instances function as a recognition molecule initiating direct activation of the alternative pathway. Factor D is a serine protease that cleaves $\mathrm{C} 3\left(\mathrm{H}_{2} \mathrm{O}\right)$ or $\mathrm{C} 3 \mathrm{~b}$-bound FB resulting in the generation of the $\mathrm{Bb}$ and formation of the alternative pathway $\mathrm{C} 3$ and $\mathrm{C} 5$ convertases. Many soluble or surface bound regulatory molecules protect the host from collateral damage mediated via complement activation. (Ricklin et al., 2010).

The lectin pathway (LP) is initiated when different pattern recognition molecules bind to pathogenassociated molecular patterns on the surface of microorganisms or altered host cells, promoting the activation of associated serine proteases, which lead to subsequent cleavage of $\mathrm{C} 4$ and $\mathrm{C} 2$ to form the C3 convertase (Endo et al., 2011). This review includes an overview of mice deficient of LP key molecules and highlights some of the important findings and lessons obtained from in vivo studies using these animals.

\section{The pattern recognition molecules}

In $1946 \mathrm{MBL}$ was originally discovered in serum as $\beta$-inhibitor that was able to inactivate influenza virus (BURNET and McCREA, 1946). In 1978 the protein, initially named mannan-binding 
protein, was extracted from rabbit liver and characterized (Kawasaki et al., 1978). Subsequently, the same group showed that MBL was present in human serum and activated complement (Kawasaki et al., 1983, Ikeda et al., 1987). As early as 1973, a ficolin was shown to exist as a thermolabile macro protein in human serum (Epstein and Tan, 1973). This protein later turned out to be ficolin-3 (Hakata antigen) (Yae et al., 1991, Sugimoto et al., 1998). In 1991 a porcine ficolin known as transforming growth factor- $\beta 1$-binding protein was isolated from pig uterus membranes (Ichijo et al., 1991), and subsequently a human homologue of the protein (ficolin-2) was isolated from plasma (Matsushita et al., 1996). In addition, a third human ficolin (ficolin-1) was identified (Lu et al., 1996). Recently, collectin-11 (CL-11, CL-K1) was also identified as a molecule that associates with lectin pathway associated serine proteases (MASPs) enabling activation of complement via LP (Keshi et al., 2006, Hansen et al., 2010, Ma et al., 2013). A mouse line deficient in CL-11 is not yet described in the literature, thus CL-11 is not included in the current review. An overview of the knockout mice deficient LP recognition molecules is shown in table 1.

\subsection{Genetics and structure of lectin pathway recognition molecules}

\subsection{1. $M B L$}

The human MBL gene is named MBL2 and located on chromosome 10q11.2-21(Sastry et al., 1989). Closely positioned to MBL2 is MBL1P1 which is a pseudogene (Guo et al., 1998), and it is believed that the two genes arise from a common ancestral MBL gene (Sastry et al., 1995). Mice, however, express two distinct functional genes, $M b l-a$ and $M b l-c$, that are positioned at different chromosomes (14 and 19 respectively), encoding two different forms of MBL (White et al., 1994). The liver is the major site of expression for both mouse MBL-genes as well as for the human $M B L 2$-gene. Mbl-c appears to be the mouse orthologue of $M B L 2$, while $M b l-a$ is the orthologue of MBL1P1. The overall structure of the two murine gene products, MBL-A and MBL-C, is similar and the homology between them is about $50 \%$, whereas human MBL is about $60 \%$ identical to the murine forms. It is believed that an ancient $\mathrm{MBL}$ gene duplicated prior to human-murine divergence, and that the functionality of the human orthologue to Mbl-a, MBL1P1, was lost during evolution at the transition from lower to higher primates (Sastry et al., 1995, Seyfarth et al., 2005). The human MBL2 gene harbors multiple polymorphisms, some of which affect the function or level of MBL (for reviews see (Garred et al., 2003, Garred et al., 2006). Functional MBL deficiency is very frequent $(5-10 \%)$ in healthy individuals (Garred et al., 2003) and the level of MBL has been 
associated with infectious disease in several studies (Takahashi and Ezekowitz, 2005). MBL belong to the collectin family of proteins, which are characterized by a collagen-like region and a C-type carbohydrate recognition domain (CRD) in their C-terminal end (figure 1). MBL has an oligomeric structure, built of triple helical structures that contain three identical polypeptides. The proteinencoding region of MBL2 consists of four exons interrupted by three introns. Exon 1 encodes the signal peptide, a cysteine rich domain and seven copies of a repeated Glycine motif (Gly-Xaa-Yaa). Exon 2 contains twelve additional Gly-Xaa-Yaa repeats, exon 3 contains a neck region and exon 4 a CRD (Garred et al., 2009).

\subsubsection{Ficolins}

Three human ficolin genes have been identified; FCN1, FCN2 and FCN3, encoding ficolin-1, ficolin-2 and ficolin-3, respectively. Ficolin-2 is predominantly expressed in the liver; ficolin-3 is expressed in the liver and the lungs, whereas ficolin-1 is expressed by the bone marrow, human peripheral blood monocytes and neutrophils (Matsushita et al., 1996, Hummelshoj et al., 2008, Lu et al., 1996, Liu et al., 2005b). All three human ficolins are present in serum (Honore et al., 2008, Munthe-Fog et al., 2007, Munthe-Fog et al., 2008). Two ficolins, termed ficolin-A and ficolin-B have been identified in mice. Ficolin-A mRNA is expressed in the liver and spleen and the protein is present in plasma (Ohashi and Erickson, 1998, Fujimori et al., 1998). Ficolin-B is expressed in bone marrow (myeloid cells) and spleen, and has also recently been detected in serum in low concentrations (Liu et al., 2005a, Weber-Steffens et al., 2013, Endo et al., 2012). The primary structure of ficolin-A is approximately $80 \%$ identical to human ficolin-2, ficolin-1 and mouse ficolin-B, suggesting that these four ficolins are closely related. Detailed analysis, based on gene loci, gene organization and phylogenetic trees have indicated that ficolin-B is the mouse orthologue of human ficolin-1, and that the genes encoding ficolin-A and ficolin-2 evolved independently from a common ficolin-B/1 gene linage (Fujita et al., 2004, Garred et al., 2010). Nevertheless, in terms of distribution and function it appears that ficolin-A and ficolin-2 resemble each other and may be regarded as functional equivalents. The same apply to ficolin-B and ficolin-1 (Garred et al., 2010). Ficolin-3 has been identified only in humans and primates, and the mouse orthologue exists as a pseudogene (Endo et al., 2004).

The ficolin genes encode similar polypeptides containing a collagen-like domain and a C-terminal fibrinogen-like (FBG) domain (figure 1). The FCN3 gene is located on chromosome 1p36, whereas FCN1 and FCN2 are located on chromosome 9q34. Exon 1 of the FCN-genes encodes a signal 
peptide and the N-terminal region. Exons 2 and 3 encode the collagen-like domain, exon 4 encodes a linker region and exons 5-8 encode the FBG-domain. The ficolins exist as multimeric proteins consisting of 34-35 kDa subunits. Ficolin-1 and ficolin-2 are $79 \%$ identical at the amino acid level, whereas ficolin-3 is $48 \%$ homologous with ficolin-1 and ficolin-2. Three identical polypeptides are assembled into structural subunits through the collagen-like domain. These trimers are further assembled into higher oligomeric forms that resemble the bouquet-like structures of MBL and C1q. The collagen-like domain interacts with the MASPs, and the FBG-like domain is involved in ligand recognition. (Garred et al., 2009).

\subsection{MBL knockout mice}

The first report of an MBL-A knockout (KO) mouse was published in 2002 (Takahashi et al., 2002). In 2004, the same group published the first study to include the MBL null mouse, a strain deficient in both of the murine MBL proteins, MBL-A and MBL-C (Shi et al., 2004). Since then numerous studies have been conducted using MBL null mice to study the impact of MBL-mediated lectin-pathway activation in various animal models of infection and disease. The following sections will provide an overview of the in vivo findings from some of these studies (summarized in table 2). MBL null mice are healthy, viable, fertile and appear normal with no obvious developmental defects (Shi et al., 2004). The classical and alternative pathways are unaffected in MBL null mice, while they display impaired activation of the MBL-mediated lectin pathway (Shi et al., 2004). Furthermore, it was later revealed that MBL null mice display defective apoptotic cell clearance (diminished by $50 \%$ relative to wildtype (WT) mice), but they do not spontaneously develop autoimmune features, as has been shown for C1q KO mice (Stuart et al., 2005).

\subsubsection{MBL is a modulator of inflammation}

The MBL-A KO mouse has been examined in the caecal ligation and puncture (CLP) model of acute septic peritonitis (Takahashi et al., 2002). Based on previous studies involving absence of the classical opsonins (e.g. C3 and soluble IgM), it was hypothesized that lack of MBL-A in a similar way would result in high and early mortality of the mice after CLP. However, it was revealed that MBL-A KO mice had enhanced survival compared to WT mice, but also to C3 KO mice. The survival advantage of MBL-A KO mice was due to the lack of circulating MBL because the phenotype was partially reversed by reconstitution of mice with intravenous administration of human MBL. Furthermore, the surviving MBL-A KO mice showed reduced levels of TNF- $\alpha$ and 
IL-6 in the blood and peritoneal cavity. Therefore, a proinflammatory role of MBL-A, which could induce too powerful a response to sepsis, was suggested.

Another example that MBL contributes to deleterious inflammatory responses came from a more recent study, where MBL null mice were examined to determine the role of MBL in pandemic H1N1 and Avian H9N2 influenza A virus infections (Ling et al., 2012). When WT mice were compared with MBL null mice, the data suggested that presence of MBL caused a more severe infection by the influenza viruses, indicated by a greater weight loss as well as more severe lung inflammation and cell infiltration in pulmonary tissues of WT mice. Furthermore, WT mice showed increased production of proinflammatory cytokines and chemokines, suggesting that MBL upregulates the inflammatory response to influenza virus infection.

Supporting evidence of the role of MBL in modulating immune responses came from a mouse model of Staphylococcus aureus infection, in which serum cytokine profiles were determined in WT and MBL null mice $2 \mathrm{~h}$ after infection (Ip et al., 2008). The cytokine profiles revealed significant differences between the two groups; specifically MBL enhanced the production of a subset of proinflammatory cytokines and chemokines.

\subsection{2. $M B L$ protects against infection}

The first study to provide in vivo evidence of the key role of MBL in first-line host defense using MBL null mice was published in 2004 (Shi et al., 2004). It was reported that these mice were highly susceptible to S.aureus in an intravenous inoculation model, all dying within $48 \mathrm{~h}$, compared with $55 \%$ survival of WT mice. In contrast, intraperitoneal inoculation of S. aureus did not lead to increased complications in MBL null mice compared to WT mice, unless the mice were rendered neutropenic. Furthermore, administration of recombinant human (rh) MBL before infection partially restored the phenotype of the MBL null mice to the level of the WT mice. Thus, these results suggested a non-redundant role of MBL in restricting the spread of bacteria from the blood to the tissues under these circumstances. Subsequently, the same group generated mice deficient of both MBL and $\mathrm{C} 3$ (MBLxC3 null mice) to address the relative role of MBL and complement-dependent mechanisms during S.aureus infection (Takahashi et al., 2005). Interestingly, it was revealed that MBL has a distinctive role in S.aureus infection that is C3-independent, because the MBLxC3 null mice were more susceptible to infection than mice lacking only C3. MBL-replacement of MBLxC3 
null mice reversed the phenotype to the level of $\mathrm{C} 3$ null mice, thus confirming that the observed difference was MBL-dependent.

In addition to S.aureus infection, MBL null mice show increased susceptibility to infection with other pathogens, including other bacteria (Pseudomonas aeruginosa, following burn injury (MollerKristensen et al., 2006)), virus (Herpes simplex virus-2 (Gadjeva et al., 2004)) and fungus (Candida albicans (Held et al., 2008)). Contrasting the previously mentioned study in which MBL null mice showed decreased susceptibility to influenza A virus infection compared to WT (Ling et al., 2012), another study found that MBL null mice developed increased viral infection compared to WT mice, as measured by viral titers in the lungs (Chang et al., 2010). The discrepancy was explained by the use of different influenza A strains in the two studies (Ling et al., 2012).

Taken together, the murine models of infection have provided evidence that MBL-deficiency does indeed increase susceptibility to infection with certain pathogens. Moreover, they demonstrated that treatment with rhMBL restored host resistance to infection to WT levels. Thus, the therapeutic use of exogenous rhMBL appeared effective in treating MBL-deficiency in mice. When the susceptibility to infection in MBL null- and MBLxC3 KO mice was compared, the existence of an MBL-dependent mechanism that does not require activation of $\mathrm{C} 3$ was evident. In addition, the infection studies demonstrated that MBL possess pro-inflammatory properties. Consequently, lack of MBL might be beneficial under certain circumstances, where inflammatory responses contribute to pathologies, e.g. during sepsis. The use of MBL null mice in relation to infections has provided important information, but the translation of these results to the human situation has indeed been difficult to confirm (Casanova and Abel, 2004, Garred et al., 2006).

\subsubsection{MBL is a risk factor for tissue injury}

In animal studies, MBL has been implicated in the pathophysiology of ischemia/reperfusion (I/R) injury due to its ability to recognize self-structures. During the past decade, in vivo studies of MBL null mice have shown that MBL-deficiency is protective in I/R injuries in heart (Walsh et al., 2005, Busche et al., 2009), kidney (Moller-Kristensen et al., 2005), gut (Hart et al., 2005, Zhang et al., 2006, McMullen et al., 2006), skeletal muscle (Chan et al., 2006) and brain (Cervera et al., 2010, de la Rosa et al., 2014).

In the kidney I/R model, lack of MBL resulted in significantly less kidney damage, assessed by measuring blood urea nitrogen and creatinine levels, supported by histological examinations of the 
kidneys after I/R (Moller-Kristensen et al., 2005). Reconstitution of MBL null mice with rhMBL reestablished the renal tissue damage in a dose-dependent manner. Furthermore, less complement deposition in the kidneys of MBL null mice was seen. Thus, these data implied that MBL modulates the renal $\mathrm{I} / \mathrm{R}$ damages.

In a gastrointestinal I/R (GI/R) model three different knockout lines, C1q KO-, C2/FB KO- and MBL null mice, were investigated in order to delineate the contribution of the classical and/or lectin pathways to I/R injury (Hart et al., 2005). It was demonstrated that $\mathrm{C} 1 \mathrm{q}$ KO mice were not protected from GI/R-mediated injury. In contrast, $\mathrm{C} 2 / \mathrm{FB} \mathrm{KO}$ - and $\mathrm{MBL}$ null mice were protected from intestinal injury, neutrophil infiltration in the intestine, intestinal permeability dysfunction and secondary liver injury. Addition of rhMBL to MBL null mice reconstituted intestinal injury after $\mathrm{GI} / \mathrm{R}$, and was reversed by anti-MBL mAb treatment. Thus, it was concluded that $\mathrm{C} 2$ and MBL, but not C1q, are essential for gut injury after GI/R. However, MBL null mice were not protected from secondary lung injury and complement was deposited in the lung, leading to the conclusion that pulmonary injury after $\mathrm{GI} / \mathrm{R}$ was $\mathrm{MBL}$ and $\mathrm{C} 1 \mathrm{q}$ independent, but $\mathrm{C} 2$ dependent, and a potential role for ficolins in this model was suggested.

Later studies using MBL null mice confirmed a role for MBL in GI/R, revealing that the tissue damage was dependent on both MBL and natural IgM (Zhang et al., 2006, McMullen et al., 2006). In order to investigate whether IgM interacts with MBL to induce complement activation in vivo and in tissue injury following GI/R, a mouse line lacking both soluble IgM (sIgM) and MBL was generated (McMullen et al., 2006). The sIgM/MBL KO mice were injected with plasma from WT or MBL null mice to restore either SIgM and MBL or sIgM alone, respectively. The data indicated that both $\operatorname{IgM}$ and MBL were required for GI/R-induced complement activation and subsequent injury. Following GI/R, sIgM/MBL $\mathrm{KO}_{+\mathrm{WT}}$ plasma mice showed increased serum alanine aminotransferase levels compared to sIgM/MBL $\mathrm{KO}_{+\mathrm{MBL}}$ null plasma mice. Similarly, increased $\mathrm{C} 3$ deposition in the intestine was observed in sIgM/MBL $\mathrm{KO}_{+\mathrm{WT}}$ plasma mice compared to $\operatorname{sgM} / \mathrm{MBL}$ $\mathrm{KO}_{+\mathrm{MBL}}$ null plasma mice. Thus, this study demonstrated that interactions between IgM and MBL in vivo can induce complement activation and deposition following GI/R. A model was proposed in which IgM binds to ischemic antigens, providing a binding site for MBL subsequently leading to lectin pathway activation, which then contributes to I/R-induced tissue inflammation and injury.

Similar results were obtained in the myocardial model of $I / R(M I / R)$, where the $\operatorname{sgM} / \mathrm{MBL}$ KO mice were investigated in an analogous plasma reconstitution mouse model of MI/R (Busche et al., 
2009). Echocardiography showed that both MBL and IgM were required for MI/R-induced loss of left ventricular function. Echocardiographic observations were supported by measurements of MI/R-related leakage of troponin I as well as myocardial neutrophil infiltration. Moreover, complement activation and the resulting $\mathrm{C} 3$ deposition on the reperfused ischemic myocardium, which was known to be MBL dependent, but C1q independent, following MI/R (Walsh et al., 2005), was also dependent on the presence of IgM. These results demonstrate that MI/R-induced complement activation, inflammation, and subsequent tissue injury require both IgM and MBL, and that IgM and MBL must be interacting together to activate complement following $\mathrm{MI} / \mathrm{R}$, in accordance with the previous results from the GI/R model (McMullen et al., 2006).

Recently it was demonstrated that the natural complement inhibitor MAP-1 could attenuate MI/R injury, not only in the MBL null mice, but also in WT mice, providing a potential to therapeutically inhibit the MBL- and complement mediated tissue injury during I/R (Pavlov et al., 2012b).

In summary, these animal models demonstrated that lack of MBL was protective in ischemia reperfusion injuries in various organs. The protective effect was MBL-mediated because treatment of MBL null mice with rhMBL reversed the phenotype. It was revealed that MBL, and not C1q, was involved in tissue injury in $\mathrm{GI} / \mathrm{R}$ and $\mathrm{MI} / \mathrm{R}$, most likely through a mechanism involving activation of $\mathrm{C} 3$. Further investigations revealed that $\operatorname{IgM}$ was also required for tissue injury in GI/R and $\mathrm{MI} / \mathrm{R}$, suggesting an interaction between MBL and IgM. Although the role of complement in animal I/R models was relatively well established previously (Diepenhorst et al., 2009), the importance of each specific pathway in the initiation of $I / R$ was further elucidated by the use of MBL null mice. Thus, the previous view holding the classical pathway responsible for a great portion of the complement-mediated I/R-damage was reconsidered by studies pointing to an important role of the LP, and the sequence of molecular events leading to complement activation in $\mathrm{I} / \mathrm{R}$ injury was questioned.

In experimental models of stroke it was revealed that MBL also contributes to brain damage (Cervera et al., 2010, de la Rosa et al., 2014). The first study to address a role for MBL in experimental stroke using MBL null mice was published in 2010 (Cervera et al., 2010). Here it was demonstrated that focal cerebral $\mathrm{I} / \mathrm{R}$ in MBL null mice induced smaller infarctions as well as a better functional outcome than in WT mice. This effect was associated with decreased C3 deposition and neutrophil infiltration in the brain of MBL null mice compared with WT mice. The contribution of MBL to ischemic brain damage was further confirmed when MBL was reconstituted 
in MBL null mice. Thus, it was concluded that lack of MBL is associated with a better outcome after acute stroke in mice. Very recently the same group published a study where it was revealed that the MBL-mediated brain injury after I/R was due to promotion of local thrombosis (de la Rosa et al., 2014), thus confirming previous studies of MBL null mice that implied a pro-coagulant role of MBL (La Bonte et al., 2012, Takahashi et al., 2011).

\subsubsection{MBL contributes to coagulation}

A study investigating the specific role or mechanism of lectin-mediated coagulation in vivo was published in 2012 (La Bonte et al., 2012). $\mathrm{FeCl}_{3}$-induced thrombogenesis resulted in complete loss of carotid artery blood flow in WT mice and C2/FB KO mice. In contrast, no decrease in blood flow in MBL null mice or MASP-1/3 $\mathrm{KO}$ mice was observed following $\mathrm{FeCl}_{3}$ exposure. A role of the MBL/MASP complex for in vivo coagulation was confirmed when reconstitution with rhMBL in MBL null mice resulted in a decrease in blood flow that was comparable to WT and $\mathrm{C} 2 / \mathrm{FB} \mathrm{KO}$ mice. Similar results were observed between the WT and $\mathrm{C} 2 / \mathrm{FB} \mathrm{KO}$ mice, indicating that downstream complement activation (C3;C5b-9) was not necessary for thrombin-like activity in vivo. Consistent with the blood flow measurements, histological staining of carotid arteries revealed marked thrombus formation in arteries from WT mice following $\mathrm{FeCl}_{3}$ exposure, whereas little thrombus formation was observed in arteries from MBL null mice. When the lectin pathway was restored with rhMBL in MBL null mice, thrombus formation was again observed. No thrombus formation was observed in MASP-1/3 KO arteries, indicating that the entire MBL-MASP complex is necessary for $\mathrm{FeCl}_{3}$-induced thrombogenesis.

Another recent study using MBL null mice supports the proposed pro-coagulant activity of MBL (de la Rosa et al., 2014). Middle cerebral artery occlusion/reperfusion was performed in MBL nulland WT mice, the relative cerebral blood flow was monitored after occlusion, and the brain lesion was assessed at days 1 and 7. Cerebral blood flow at reperfusion was improved in MBL null mice compared to WT mice. In addition MBL-deficiency reduced infarct volumes, neurological impairments as well as deposition of fibrin(ogen) in brain vessels. The harmful effect of MBL was suggested to be partly mediated by thrombin activation, because treatment with the thrombin inhibitor argatroban did not influence outcome in MBL null mice, whereas it reduced infarct volume and improved neurological deficit in WT mice. Therefore it was concluded that MBL impairs cerebral circulation at reperfusion after brain ischemia, by promoting local thrombosis through a mechanism involving thrombin activation. 
The in vivo studies of MBL null mice presented here propose that MBL has important interactions with the coagulation system. A conceivable advantage of the pro-coagulant effect of LP proteins may be that activation of the coagulation system aid to the local sequestration of pathogens, thereby preventing dissemination. However, after ischemic stroke the pro-coagulant effect in injured brain vasculature could impair reperfusion and contribute to brain damage.

The MBL null mice have also been investigated in the setting of diabetes in several studies. MBLdeficiency itself does not induce a diabetic phenotype, however in the setting of both diabetes and MBL-deficiency, it might be beneficial to lack MBL in terms of MI/R (Busche et al., 2008), cardiovascular complications (Pavlov et al., 2012a) and renal changes (Ostergaard et al., 2007).

\subsection{Ficolin knockout mice}

The general phenotypes of ficolin-deficient mice were first described in 2012 (Endo et al., 2012). Three strains of ficolin-deficient mice were generated; ficolin-A (FcnA) KO, ficolin-B (FcnB) KO and a FenA- and FenB double $\mathrm{KO}(\mathrm{FcnA} / \mathrm{B} \mathrm{KO})$. None of ficolin-deficient strains display abnormality in the in their general appearance, body weight or fertility. Neither were abnormalities observed in the tissues from adult mice. In addition, no difference was observed in the peripheral blood counts and coagulation time between KO mice and WT mice. There was no ficolin-Amediated complement activation in the sera of FenA KO and FcnA/B KO mice due to the absence of ficolin-A-MASP complexes.

The role of ficolins in host defense was evaluated by intranasal infection with a Streptococcus pneumonia strain, and all three strains of ficolin-deficient mice showed reduced survival rates compared to WT mice, suggesting that ficolins play a crucial role in immunity against pneumococcal infection (Endo et al., 2012). To further confirm the defensive role of ficolins in vivo, ficolin-A was transiently expressed in FcnA KO and FenA/B KO mice by intravenous injection of a ficolin-A-encoding plasmid before infection. Reconstitution of ficolin-A improved the survival rate of FenA KO mice, but not of FenA/B KO mice, revealing the requirement of both ficolin-A and ficolin-B for combatting S. pneumonia.

Ficolin-A knockout mice have also been used in a mouse model of influenza A virus infection (Pan et al., 2012). Initially, WT mice were intramuscularly injected with a plasmid to induce human ficolin-2 expression, and it was demonstrated that ficolin-2 was expressed at the injection site and released into the circulation and lung tissue. After influenza A infection, the ficolin-2 expressing 
mice showed decreased hemagglutinin (HA) titers of lung homogenates, no weight-loss and decreased inflammatory cell infiltration of the lungs compared to mice injected with a control vector, suggesting that ficolin-2 protected the WT mice from influenza A virus. Subsequently, ficolin-A or ficolin-2 was transiently expressed in FcnA KO mice. The results showed that FcnA KO mice were more susceptible to infection compared to WT mice, and moreover, that the FcnA $\mathrm{KO}$ mice that were injected with ficolin-2 or ficolin-A showed prolonged survival time compared to control groups injected with saline or an empty vector. Accordingly, reduced viral RNA expression, hemagglutinin titers, viral replication as well as less inflammation and leukocyte infiltration, was observed in lungs of ficolin-2 and ficolin-A plasmid groups. Thus, this study suggests a protective role of ficolin-A in influenza $\mathrm{A}$ infection, and that administration of ficolin-2 or ficolin-A can improve host resistance to infection.

The same group also investigated FcnA KO mice in an infection model of Mycobacterium Tuberculosis (Luo et al., 2013). Again, WT mice were transfected with a ficolin-2 vector. After infection with $M$. tuberculosis, the ficolin-2-administrated mice exhibited prolonged survival time, as well as decreased viable bacterial counts in the lung and spleen tissues compared to control groups. In addition, a decreased survival rate of infected FcnA KO mice compared to WT mice was observed, and administration of ficolin-2 or ficolin-A also prolonged the survival time of FcnA KO mice. Further experiments in which mice were injected with LPS revealed that FcnA KO mice produced lower levels of TNF-alpha and IL-17 at $3 \mathrm{~h}$ compared to WT mice. Collectively, these data propose a proinflammatory function of ficolin-A and substantiates the implication of ficolin-A and ficolin-2 in host defense against infection.

Although MBL-deficient mice have been widely used to investigate the role of MBL, the investigation of ficolin-deficient mice is merely initiated, and at present only a limited number of reports have been published (summarized in table 2). Nevertheless, these studies have confirmed the importance of ficolins in protection against certain pathogens in vivo, and indeed the ficolin $\mathrm{KO}$ mice will provide important new knowledge of the role biological roles of ficolins and the lectin pathway in future research.

\section{MBL-associated serine proteases (MASPs)}

In 1987 it was shown that an MBL containing fraction, separated from human serum, could activate complement by cleaving C4 and C2, resembling the classical pathway (Ikeda et al., 1987). The 
pattern-recognition molecules of the LP require their associated serum serine protease to cleave the complement components, but until a distinct serum serine protease was isolated, it was anticipated that C1r and C1s would be the responsible enzymes to cleave C4 and C2. In 1992, Matsushita et al. originally identified a C1s-like serine protease, designated MBL-associated serine protease (MASP) that is distinct from $\mathrm{C} 1 \mathrm{r}$ and $\mathrm{C} 1 \mathrm{~s}$, from a fraction containing $\mathrm{MBL}$ by affinity chromatography (Matsushita and Fujita, 1992).

The domain structure of MASP is similar to that of C1r and C1s of the classical pathway (Sato et al., 1994). However, it was assumed that LP activation was more complicated than CP activation, because two additional MASPs (MASP-2 and MASP-3, the originally identified MASP found by Matsushita et al. is now called MASP-1, instead of MASP) were found in MBL-MASP complexes (Thiel et al., 1997, Dahl et al., 2001). Later the ficolins were found to be associated with the MASPs (Matsushita et al., 2000, Matsushita et al., 2002, Liu et al., 2005b). In addition to MBL and the ficolins, CL-11 also form complexes with the MASPs and activates LP (Ma et al., 2013). Furthermore, the truncated gene products named MAP-1 (also known as Map44) and sMAP (also known as Map19 or MAP-2) without serine protease activity are also found in these complexes

(Degn et al., 2009, Stover et al., 1999, Takahashi et al., 1999) MASP-2 has an activity to cleave C4 and C2 while MASP-1 activates MASP-2 and cleaves C2 and is essential for LP activation (Heja et al., 2012). However, the functional characteristics of the remaining proteases MASP-3, are only recently starting to be elucidated.

\subsection{Gene structure of MASPs}

MASP consists of six well-conserved domains: two $\mathrm{C} 1 \mathrm{r} / \mathrm{C} 1 \mathrm{~s} /$ embryonic sea Urchin protein/Bonemorphogenetic protein (CUB) domains, an epidermal growth factor (EGF)-like domain, two complement control protein (CCP) or short consensus repeat (SCR) domains, and a serine protease domain (CUB-EGF-CUB-CCP-CCP-SP), which is similar to C1r and C1s in the CP (figure 2) (Fujita, 2002, Matsushita et al., 1998). In mammals, two genes (MASP1 and MASP2) are responsible to express all MASP-related products. MASP-1 and MASP-3 consist of a common heavy chain and the distinct catalytic domain (serine protease, SP). The MASP1 gene structure is unique, because distinct exons, encoding SP domain of MASP-3 and MASP-1 respectively, tandem locates downstream of split exons encoding a common heavy chain (figure 2). Recent studies have identified an alternative splicing product from the MASP1 gene, encoding a truncated non-catalytic 
protein transcript generating MAP-1 (Map44) that contains exons 1-8 and a novel exon encoding an in-frame stop codon. The corresponding protein lacks the serine protease domains but contains most of the common heavy chain of MASP-1 and MASP-3. Additionally MAP-1 contains 17 unique Cterminal amino acids (Degn et al., 2009, Skjoedt et al., 2010). The MASP2 gene also give rise to two alternative splice variants: the MASP-2 protein and a truncated version named sMAP (Map19 or MAP-2) containing parts of the common heavy chain lacking the serine protease domain, but comprising 4 unique amino acids (figure 2) (Takahashi et al., 1999, Stover et al., 1999).

\subsection{MASP knockout mice}

To investigate the roles of each MASP protease, the targeted disruptions of the MASP1 and MASP2 genes in mice were performed (Iwaki et al., 2006, Takahashi et al., 2008). To generate Masp1 knockout mouse, the second exon, encoding the signal peptide of MASP-1 and MASP-3, was selected to be replaced by a neo-cassette (Takahashi et al., 2008). After the Masp1-/- mouse has been established, MASP-3 was discovered. It was confirmed that the Masp1-/- mouse also lacks MASP-3, therefore, this strain is generally called Masp1/3-/- instead of Masp1-/-. It was noticed that the Masp1/3-/- mice were smaller than the control mice (Takahashi et al., 2008). In addition it was observed that these mice showed abnormalities in their adipose tissue composition suggesting a crucial role for MASP-1/3 in lipid metabolism. A Masp2 gene-disrupted mouse has been developed by replacing the sMAP/Map19/MAP-2-specific exon with a neo-cassette (Iwaki et al., 2006). It was shown that this knockout mouse defects the MASP-2 product in addition to the sMAP/Map19/MAP-2 product, thus, it was designated the Masp2/smap-/- mouse. Moreover, an all MASP deficient mouse (all MASP KO) was established by mating Masp1/3-/- and Masp2/smap-/mice. In addition, another MASP-2-deficient mouse (with intact sMAP) has been developed (Schwaeble et al., 2011).

\subsubsection{Roles of MASPs in the LP activation}

In the MASP-mediated LP activation, the consensus seems to be that MASP-2 can autonomously cleave C4 and C2, following the activation of complement cascade (Chen and Wallis, 2004, VorupJensen et al., 2000). This was evidenced in 2003 by a report of inherited deficiency of MASP-2 (Stengaard-Pedersen et al., 2003). In this report, a missense mutation located on the CUB1 domain of MASP-2 was found in a patient who showed increased susceptibility to infection. The patient's 
MASP-2 could not associate with MBL and serum derived from the patient showed low C4 deposition on mannan-coated wells. Another report described that the recombinant MASP-2 alone is sufficient to activate the LP by cleaving C4 and C2 (Vorup-Jensen et al., 2000). Since MASP-2 alone can cleave $\mathrm{C} 4$ and $\mathrm{C} 2$, sufficient to activate the $\mathrm{C} 3$ convertase, $\mathrm{C} 4 \mathrm{~b} 2 \mathrm{a}$, it was predicted that the Masp2/smap-/- mouse would show defects in LP activation. When Masp2/smap-/- mouse serum was incubated on mannan, the $\mathrm{C} 4$ and $\mathrm{C} 3$ depositions were reduced compared with those in WT serum (Iwaki et al., 2006). Altogether, MASP-2 is cleaving C4 and C2.

Whether MASP-1 and MASP-3 contribute to LP activation has been debated. The Masp1/3-/mouse has provided important information to resolve this question. Takahashi et al. investigated the activity of the LP in Masp1/3-/- mice and reported that Masp1/3-/- mice showed low C4 cleavage ability which was associated with low MASP-2 activation (Takahashi et al., 2008). This fact revealed that MASP-1 contributes the LP activation via promoting the activation of MASP-2. This issue has now clearly been documented using specific inhibitors of MASP-1 and MASP-2 as well as MASP-1 deficient serum showing that MASP-1 is a prerequisite from activation of MASP-2 and contributes to C2 activation under physiological conditions (figure 3) (Heja et al., 2012, Degn et al., 2012).

\subsubsection{MASP-1 and MASP-3 contribute to alternative pathway activation}

In 1989, Schweinle et al. demonstrated that MBL-mediated deposition of C3 on Salmonella strains occurs via the alternative pathway (AP) (Schweinle et al., 1989). Therefore, to investigate whether the AP is affected in Masp1/3-/- mice, murine sera were assayed for hemolytic activity against rabbit erythrocytes and for $\mathrm{C} 3$ deposition ability on zymosan-coated wells to prevent the $\mathrm{CP}$ activation by EGTA. Both assays showed that Masp1/3-/- sera had no ability to activate the AP (Takahashi et al., 2010).

During AP activation, complement factor D (FD) is produced from adipocytes and is immediately converted to an active-form by releasing five amino acids (activating peptide) at the N-terminal part of pro-FD during secretion. Takahashi et al. found that circulating FD in Masp1/3-/- mice is slightly larger than that in WT mice by Western blotting, and FD in Masp1/3-/- mice proved to be a proenzyme form that contains five amino acids at the N-terminal of active FD by mass spectrometrical analysis (Takahashi et al., 2010). Iwaki et al. also showed that MASP-3 is able to cleave FD, which is similar to that observed for MASP-1 (Iwaki et al., 2011). These evidences 
support that MASP-1 and MASP-3 are important enzymes to activate pro-FD to active FD in mice and thus contribute to AP activation (figure 3).

\subsubsection{Collagen antibody induced arthritis (CAIA) model in mouse}

Collagen antibody induced arthritis (CAIA) is amplified by the AP and inhibition of this pathway ameliorate the onset and severity of CAIA (Banda et al., 2007). Since MASP-1 and MASP-3 are crucial for AP activation via FD activation, it was examined whether the expression of MASP-1/3 is essential for the development of CAIA (Banda et al., 2010). In the report, it was shown that Masp1/3-/- mice are highly resistant to CAIA as evidenced by a significant decrease compared to WT mice (Banda et al., 2010). This evidence strongly supports that MASP-1 and MASP-3 is required for the AP activation in vivo.

\subsubsection{C3 dysregulation due to factor H deficiency is independent of MASP-1 and MASP-3 in mice}

In complete complement factor $\mathrm{H}(\mathrm{FH})$ deficiency, uncontrolled $\mathrm{C} 3$ activation through the alternative pathway results in plasma $\mathrm{C} 3$ depletion and complement-mediated renal disease. In a mouse model co-deficient of both FH and MASP-1/MASP-3 the plasma C3 activation or glomerular C3 accumulation was not ameliorated indicating that MASP-1 and MASP-3 are not essential for alternative pathway activation in complete FH deficiency, but rather maybe contributing factors (Ruseva et al., 2014). Thus, dependent on the assays system and models employed the MASPs may be more or less involved in alternative pathway initiation and amplification in addition to at present other unknown mechanisms.

\subsubsection{MASP-2 contributes to tissue injury}

The MASP-2-deficient mouse has been used in models of I/R (Schwaeble et al., 2011). In the MI/R model, the MASP-2-deficient mice had significantly smaller infarction volumes than WT mice. Furthermore, mice lacking C4 were not protected from injury, suggesting the existence of a LPdependent C4 bypass. In addition, the MASP-2 deficient mice were protected in a GI/R model. A very recent study confirmed a role for MASP-2 in tissue injury (Asgari et al., 2014). In a mouse model of renal transplantation, WT grafts transplanted into MASP-2 deficient recipients resulted in better kidney function, less C3 deposition and less I/R injury compared to when WT kidneys were grafted into WT recipients. The results also indicated that injury occurred through MASP-2 dependent activation events independent of $\mathrm{C} 4$. 


\subsection{Human MASP1/3 gene mutations}

The Carnevale, Mingarelli, Malpuech and Michels syndromes are four rare autosomal recessive disorders (Carnevale et al., 1989, Malpuech et al., 1983, Michels et al., 1978, Mingarelli et al., 1996). They were recently postulated to be part of the same clinical entity termed the "3MC syndrome". Recent research identified two responsible genes, MASP1 and COLEC11, for developing the disorders of 3MC syndrome (Rooryck et al., 2011). Collectin-11 that is encoded by the COLEC11 gene, is one of the pattern-recognition molecules of LP and associated with MASP proteases (Hansen et al., 2010, Keshi et al., 2006, Ma et al., 2013). So far, six point mutations in the MASP1 gene were identified among 3MC patients (Rooryck et al., 2011, Sirmaci et al., 2010). It should be noticed that no mutations in the MASP-1 specific exons has been found in $3 \mathrm{MC}$ syndrome patients, indicating that MASP-3, but not MASP-1, may be involved in the abnormality of early development in 3MC syndrome patients. This fact proposed that MASP-3, associated with CL-11 could cleave an unknown targeted protein, which is required in embryogenesis and probably during neural crest migration (figure 3). Preliminary results show that the Masp1/3-/- mice also have development problems in agreement with the human situation (unpublished results).

Human MASP-1 and/or MASP-3-deficient sera from 3MC patients have been investigated. It has been reported that the $\mathrm{AP}$ in a serum from a $3 \mathrm{MC}$ syndrome patient was comparable with that of normal control sera (Degn et al., 2012). This result is inconsistent with the observation using serum derived from Masp1/3-/- mice showing decreased AP activity (Takahashi et al., 2010). However, Takahashi and colleagues demonstrated that recombinant human MASP-1 can cleave human proFD, indicating that it is likely that MASP-1 and MASP-3 are not essential for AP activation in humans, but indeed have a role in AP activation (Takahashi et al., 2013).

\section{Concluding remarks}

Research over the past decade using mice deficient in LP molecules has revealed that the role of LP and complement in general is far more complex than previously anticipated. It has become evident that the pattern-recognition molecules are implicated in many other (non)immunological aspects than pattern recognition. Indeed studies of knockout mice have revealed the complicated physiology of the LP, providing evidence of involvement of LP in protection from infection, but also in mediating tissue injury and coagulation that can be harmful to the host. In addition, the studies of 
MASP knockout mice have indicated that MASP-1 and MASP-3 apparently influences the AP in addition to the LP, but this is still an area that needs to be resolved in detail. Furthermore, MASP-3 and collectin-11 might be involved in embryogenesis, indicating crucial roles for the LP outside innate immunity and inflammation. Thus, the animal models deficient in LP molecules have provided researchers with a powerful tool to investigate the in vivo role of LP and its associated molecules, and hopefully these animal models will not only help elucidate the biology of LP, but also prove to be of great value in terms of refining therapy and prevention of disease and injury in humans. 


\section{Acknowledgement}

We thank Dr. Lea Munthe-Fog (Copenhagen, Denmark) for help with illustrations. NG and PG were financially supported by The Danish Research Council of Medical Research, The Novo Nordisk Research Foundation, The Lundbeck Research Foundation, The Svend Andersen Research Foundation, Rigshospitalet and The University of Copenhagen. MT, HS, YE, and TF were financially supported by Grant-in-Aid for Scientific Research from the Ministry of Education, Culture, Sports, Science, and Technology of Japan as well as by the Core Research of Evolutional Science and Technology, Japan Science and Technology Agency. 


\section{Figure legends}

Fig. 1. Prototypic structures of mannose-binding lectin (MBL) (upper panels) and ficolin (lower panels) genes and monomers. Each monomeric polypeptide contains: an N-terminal cysteine-rich region cross linking the polypeptides; a collagen-like domain; a neck/linker region; and a Cterminal carbohydrate-recognition domain (CRD) in MBLs and a fibrinogen-like (FBG) domain in ficolins.

Fig. 2. A Schematic representation of the MASP-1 and MASP-2 domain structures. MASP-1, MASP-3 and MAP-1 is derived from the MASP1 gene by alternative splicing. MASP-2 and sMAP are derived from MASP2 gene by alternative splicing. All MASP related products contain a wellconserved domain structure.

Fig. 3 Schematic representation of possible biological roles of the MASPs. Left shows the involvement of MASP-1 and MASP-2 in lectin pathway activation. Middle panel shows the possible role of MASP-1 and MASP-3 in alternative pathway activation. Right panel shows the possible role of MASP-3 in embryogenesis. 


\section{References}

Asgari, E., Farrar, C.A., Lynch, N., Ali, Y.M., Roscher, S., Stover, C., Zhou, W., Schwaeble, W.J., Sacks, S.H. 2014. Mannan-binding lectin-associated serine protease 2 is critical for the development of renal ischemia reperfusion injury and mediates tissue injury in the absence of complement C4. FASEB J doi: 10.1096/fj.13-246306 .

Banda, N.K., Takahashi, K., Wood, A.K., Holers, V.M., Arend, W.P. 2007. Pathogenic complement activation in collagen antibody-induced arthritis in mice requires amplification by the alternative pathway. J. Immunol. 179, 4101-4109.

Banda, N.K., Takahashi, M., Levitt, B., Glogowska, M., Nicholas, J., Takahashi, K., Stahl, G.L., Fujita, T., Arend, W.P., Holers, V.M. 2010. Essential role of complement mannose-binding lectinassociated serine proteases-1/3 in the murine collagen antibody-induced model of inflammatory arthritis. J. Immunol. 185, 5598-5606.

Burnet, F.M. McCrea, J.F. 1946. Inhibitory and activating action of normal ferret sera against an influenza virus strain. Aust. J. Exp. Biol. Med. Sci. 24, 277-282.

Busche, M.N., Pavlov, V., Takahashi, K., Stahl, G.L. 2009. Myocardial ischemia and reperfusion injury is dependent on both IgM and mannose-binding lectin. Am. J. Physiol Heart Circ. Physiol 297, H1853-H1859.

Busche, M.N., Walsh, M.C., McMullen, M.E., Guikema, B.J., Stahl, G.L. 2008. Mannose-binding lectin plays a critical role in myocardial ischaemia and reperfusion injury in a mouse model of diabetes. Diabetologia 51, 1544-1551.

Carnevale, F., Krajewska, G., Fischetto, R., Greco, M.G., Bonvino, A. 1989. Ptosis of eyelids, strabismus, diastasis recti, hip defect, cryptorchidism, and developmental delay in two sibs. Am. J. Med. Genet. 33, 186-189.

Casanova, J.L. Abel, L. 2004. Human Mannose-binding Lectin in Immunity: Friend, Foe, or Both? J. Exp. Med. 199, 1295-1299. 
Cervera, A., Planas, A.M., Justicia, C., Urra, X., Jensenius, J.C., Torres, F., Lozano, F., Chamorro, A. 2010. Genetically-defined deficiency of mannose-binding lectin is associated with protection after experimental stroke in mice and outcome in human stroke. PLoS. One. 5, e8433.

Chan, R.K., Ibrahim, S.I., Takahashi, K., Kwon, E., McCormack, M., Ezekowitz, A., Carroll, M.C., Moore, F.D., Jr., Austen, W.G., Jr. 2006. The differing roles of the classical and mannose-binding lectin complement pathways in the events following skeletal muscle ischemia-reperfusion. J. Immunol. 177, 8080-8085.

Chang, W.C., White, M.R., Moyo, P., McClear, S., Thiel, S., Hartshorn, K.L., Takahashi, K. 2010. Lack of the pattern recognition molecule mannose-binding lectin increases susceptibility to influenza A virus infection. BMC. Immunol. 11, 64.

Chen, C.B. Wallis, R. 2004. Two mechanisms for mannose-binding protein modulation of the activity of its associated serine proteases. J. Biol. Chem. 279, 26058-26065.

Dahl, M.R., Thiel, S., Matsushita, M., Fujita, T., Willis, A.C., Christensen, T., Vorup-Jensen, T., Jensenius, J.C. 2001. MASP-3 and its association with distinct complexes of the mannan-binding lectin complement activation pathway. Immunity. 15, 127-135.

de la Rosa, X., Cervera, A., Kristoffersen, A.K., Valdes, C.P., Varma, H.M., Justicia, C., Durduran, T., Chamorro, A., Planas, A.M. 2014. Mannose-binding lectin promotes local microvascular thrombosis after transient brain ischemia in mice. Stroke 45, 1453-1459.

Degn, S.E., Hansen, A.G., Steffensen, R., Jacobsen, C., Jensenius, J.C., Thiel, S. 2009. MAp44, a human protein associated with pattern recognition molecules of the complement system and regulating the lectin pathway of complement activation. J. Immunol. 183, 7371-7378.

Degn, S.E., Jensen, L., Hansen, A.G., Duman, D., Tekin, M., Jensenius, J.C., Thiel, S. 2012. Mannan-binding lectin-associated serine protease (MASP)-1 is crucial for lectin pathway activation in human serum, whereas neither MASP-1 nor MASP-3 is required for alternative pathway function. J. Immunol. 189, 3957-3969.

Diepenhorst, G.M., van Gulik, T.M., Hack, C.E. 2009. Complement-mediated ischemia-reperfusion injury: lessons learned from animal and clinical studies. Ann. Surg. 249, 889-899. 
Endo, Y., Liu, Y., Kanno, K., Takahashi, M., Matsushita, M., Fujita, T. 2004. Identification of the mouse $H$-ficolin gene as a pseudogene and orthology between mouse ficolins A/B and human L-/Mficolins. Genomics 84, 737-744.

Endo, Y., Matsushita, M., Fujita, T. 2011. The role of ficolins in the lectin pathway of innate immunity. Int. J. Biochem. Cell Biol. 43, 705-712.

Endo, Y., Takahashi, M., Iwaki, D., Ishida, Y., Nakazawa, N., Kodama, T., Matsuzaka, T., Kanno, K., Liu, Y., Tsuchiya, K., Kawamura, I., Ikawa, M., Waguri, S., Wada, I., Matsushita, M., Schwaeble, W.J., Fujita, T. 2012. Mice deficient in ficolin, a lectin complement pathway recognition molecule, are susceptible to Streptococcus pneumoniae infection. J. Immunol. 189, 5860-5866.

Epstein, W.V. Tan, M. 1973. An antibody-like material in systemic lupus erythematosus directed toward a thermolabile serum macroprotein. Arthritis Rheum. 16, 43-51.

Fujimori, Y., Harumiya, S., Fukumoto, Y., Miura, Y., Yagasaki, K., Tachikawa, H., Fujimoto, D. 1998. Molecular cloning and characterization of mouse ficolin-A. Biochem. Biophys. Res. Commun. 244, 796-800.

Fujita, T. 2002. Evolution of the lectin-complement pathway and its role in innate immunity. Nat. Rev. Immunol. 2, 346-353.

Fujita, T., Matsushita, M., Endo, Y. 2004. The lectin-complement pathway--its role in innate immunity and evolution. Immunol. Rev. 198, 185-202.

Gadjeva, M., Paludan, S.R., Thiel, S., Slavov, V., Ruseva, M., Eriksson, K., Lowhagen, G.B., Shi, L., Takahashi, K., Ezekowitz, A., Jensenius, J.C. 2004. Mannan-binding lectin modulates the response to HSV-2 infection. Clin. Exp. Immunol. 138, 304-311.

Garred, P., Honore, C., Ma, Y.J., Munthe-Fog, L., Hummelshoj, T. 2009. MBL2, FCN1, FCN2 and FCN3-The genes behind the initiation of the lectin pathway of complement. Mol. Immunol. 46, 2737-2744.

Garred, P., Honore, C., Ma, Y.J., Rorvig, S., Cowland, J., Borregaard, N., Hummelshoj, T. 2010. The genetics of ficolins. J. Innate. Immun. 2, 3-16. 
Garred, P., Larsen, F., Madsen, H.O., Koch, C. 2003. Mannose-binding lectin deficiency--revisited. Mol. Immunol. 40, 73-84.

Garred, P., Larsen, F., Seyfarth, J., Fujita, R., Madsen, H.O. 2006. Mannose-binding lectin and its genetic variants. Genes Immun. 7, 85-94.

Guo, N., Mogues, T., Weremowicz, S., Morton, C.C., Sastry, K.N. 1998. The human ortholog of rhesus mannose-binding protein-A gene is an expressed pseudogene that localizes to chromosome 10. Mamm. Genome 9, 246-249.

Hansen, S., Selman, L., Palaniyar, N., Ziegler, K., Brandt, J., Kliem, A., Jonasson, M., Skjoedt, M.O., Nielsen, O., Hartshorn, K., Jorgensen, T.J., Skjodt, K., Holmskov, U. 2010. Collectin 11 (CL11, CL-K1) is a MASP-1/3-associated plasma collectin with microbial-binding activity. J. Immunol. 185, 6096-6104.

Hart, M.L., Ceonzo, K.A., Shaffer, L.A., Takahashi, K., Rother, R.P., Reenstra, W.R., Buras, J.A., Stahl, G.L. 2005. Gastrointestinal ischemia-reperfusion injury is lectin complement pathway dependent without involving C1q. J. Immunol. 174, 6373-6380.

Heja, D., Kocsis, A., Dobo, J., Szilagyi, K., Szasz, R., Zavodszky, P., Pal, G., Gal, P. 2012. Revised mechanism of complement lectin-pathway activation revealing the role of serine protease MASP-1 as the exclusive activator of MASP-2. Proc. Natl. Acad. Sci. U. S. A 109, 10498-10503.

Held, K., Thiel, S., Loos, M., Petry, F. 2008. Increased susceptibility of complement factor B/C2 double knockout mice and mannan-binding lectin knockout mice to systemic infection with Candida albicans. Mol. Immunol. 45, 3934-3941.

Honore, C., Rorvig, S., Munthe-Fog, L., Hummelshoj, T., Madsen, H.O., Borregaard, N., Garred, P. 2008. The innate pattern recognition molecule Ficolin-1 is secreted by monocytes/macrophages and is circulating in human plasma. Mol. Immunol. 45, 2782-2789.

Hummelshoj, T., Fog, L.M., Madsen, H.O., Sim, R.B., Garred, P. 2008. Comparative study of the human ficolins reveals unique features of Ficolin-3 (Hakata antigen). Mol. Immunol. 45, 16231632. 
Ichijo, H., Ronnstrand, L., Miyagawa, K., Ohashi, H., Heldin, C.H., Miyazono, K. 1991. Purification of transforming growth factor-beta 1 binding proteins from porcine uterus membranes. J. Biol. Chem. 266, 22459-22464.

Ikeda, K., Sannoh, T., Kawasaki, N., Kawasaki, T., Yamashina, I. 1987. Serum lectin with known structure activates complement through the classical pathway. J. Biol. Chem. 262, 7451-7454.

Ip, W.K., Takahashi, K., Moore, K.J., Stuart, L.M., Ezekowitz, R.A. 2008. Mannose-binding lectin enhances Toll-like receptors 2 and 6 signaling from the phagosome. J. Exp. Med. 205, 169-181.

Iwaki, D., Kanno, K., Takahashi, M., Endo, Y., Lynch, N.J., Schwaeble, W.J., Matsushita, M., Okabe, M., Fujita, T. 2006. Small mannose-binding lectin-associated protein plays a regulatory role in the lectin complement pathway. J. Immunol. 177, 8626-8632.

Iwaki, D., Kanno, K., Takahashi, M., Endo, Y., Matsushita, M., Fujita, T. 2011. The role of mannose-binding lectin-associated serine protease-3 in activation of the alternative complement pathway. J. Immunol. 187, 3751-3758.

Kawasaki, N., Kawasaki, T., Yamashina, I. 1983. Isolation and characterization of a mannanbinding protein from human serum. J. Biochem. 94, 937-947.

Kawasaki, T., Etoh, R., Yamashina, I. 1978. Isolation and characterization of a mannan-binding protein from rabbit liver. Biochem. Biophys. Res. Commun. 81, 1018-1024.

Keshi, H., Sakamoto, T., Kawai, T., Ohtani, K., Katoh, T., Jang, S.J., Motomura, W., Yoshizaki, T., Fukuda, M., Koyama, S., Fukuzawa, J., Fukuoh, A., Yoshida, I., Suzuki, Y., Wakamiya, N. 2006. Identification and characterization of a novel human collectin CL-K1. Microbiol. Immunol. 50, 1001-1013.

La Bonte, L.R., Pavlov, V.I., Tan, Y.S., Takahashi, K., Takahashi, M., Banda, N.K., Zou, C., Fujita, T., Stahl, G.L. 2012. Mannose-binding lectin-associated serine protease-1 is a significant contributor to coagulation in a murine model of occlusive thrombosis. J. Immunol. 188, 885-891.

Ling, M.T., Tu, W., Han, Y., Mao, H., Chong, W.P., Guan, J., Liu, M., Lam, K.T., Law, H.K., Peiris, J.S., Takahashi, K., Lau, Y.L. 2012. Mannose-binding lectin contributes to deleterious inflammatory response in pandemic H1N1 and avian H9N2 infection. J. Infect. Dis. 205, 44-53. 
Liu, Y., Endo, Y., Homma, S., Kanno, K., Yaginuma, H., Fujita, T. 2005a. Ficolin A and ficolin B are expressed in distinct ontogenic patterns and cell types in the mouse. Mol. Immunol. 42, 12651273.

Liu, Y., Endo, Y., Iwaki, D., Nakata, M., Matsushita, M., Wada, I., Inoue, K., Munakata, M., Fujita, T. 2005b. Human M-ficolin is a secretory protein that activates the lectin complement pathway. J. Immunol. 175, 3150-3156.

Lu, J., Tay, P.N., Kon, O.L., Reid, K.B. 1996. Human ficolin: cDNA cloning, demonstration of peripheral blood leucocytes as the major site of synthesis and assignment of the gene to chromosome 9. Biochem. J. 313 ( Pt 2), 473-478.

Luo, F., Sun, X., Wang, Y., Wang, Q., Wu, Y., Pan, Q., Fang, C., Zhang, X.L. 2013. Ficolin-2 defends against virulent Mycobacteria tuberculosis infection in vivo, and its insufficiency is associated with infection in humans. PLoS. One. 8, e73859.

Ma, Y.J., Skjoedt, M.O., Garred, P. 2013. Collectin-11/MASP complex formation triggers activation of the lectin complement pathway--the fifth lectin pathway initiation complex. J. Innate. Immun. 5, 242-250.

Malpuech, G., Demeocq, F., Palcoux, J.B., Vanlieferinghen, P. 1983. A previously undescribed autosomal recessive multiple congenital anomalies/mental retardation (MCA/MR) syndrome with growth failure, lip/palate cleft(s), and urogenital anomalies. Am. J. Med. Genet. 16, 475-480.

Matsushita, M., Endo, Y., Fujita, T. 2000. Cutting edge: complement-activating complex of ficolin and mannose-binding lectin-associated serine protease. J. Immunol. 164, 2281-2284.

Matsushita, M., Endo, Y., Nonaka, M., Fujita, T. 1998. Complement-related serine proteases in tunicates and vertebrates. Curr. Opin. Immunol. 10, 29-35.

Matsushita, M., Endo, Y., Taira, S., Sato, Y., Fujita, T., Ichikawa, N., Nakata, M., Mizuochi, T. 1996. A novel human serum lectin with collagen- and fibrinogen-like domains that functions as an opsonin. J. Biol. Chem. 271, 2448-2454.

Matsushita, M. Fujita, T. 1992. Activation of the classical complement pathway by mannosebinding protein in association with a novel C1s-like serine protease. J. Exp. Med. 176, 1497-1502. 
Matsushita, M., Kuraya, M., Hamasaki, N., Tsujimura, M., Shiraki, H., Fujita, T. 2002. Activation of the lectin complement pathway by H-ficolin (Hakata antigen). J. Immunol. 168, 3502-3506.

McMullen, M.E., Hart, M.L., Walsh, M.C., Buras, J., Takahashi, K., Stahl, G.L. 2006. Mannosebinding lectin binds IgM to activate the lectin complement pathway in vitro and in vivo. Immunobiology 211, 759-766.

Michels, V.V., Hittner, H.M., Beaudet, A.L. 1978. A clefting syndrome with ocular anterior chamber defect and lid anomalies. J. Pediatr. 93, 444-446.

Mingarelli, R., Castriota, S.A., Dallapiccola, B. 1996. Two sisters with a syndrome of ocular, skeletal, and abdominal abnormalities (OSA syndrome). J. Med. Genet. 33, 884-886.

Moller-Kristensen, M., Ip, W.K., Shi, L., Gowda, L.D., Hamblin, M.R., Thiel, S., Jensenius, J.C., Ezekowitz, R.A., Takahashi, K. 2006. Deficiency of mannose-binding lectin greatly increases susceptibility to postburn infection with Pseudomonas aeruginosa. J. Immunol. 176, 1769-1775.

Moller-Kristensen, M., Wang, W., Ruseva, M., Thiel, S., Nielsen, S., Takahashi, K., Shi, L., Ezekowitz, A., Jensenius, J.C., Gadjeva, M. 2005. Mannan-binding lectin recognizes structures on ischaemic reperfused mouse kidneys and is implicated in tissue injury. Scand. J. Immunol. 61, 426434.

Munthe-Fog, L., Hummelshoj, T., Hansen, B.E., Koch, C., Madsen, H.O., Skjodt, K., Garred, P. 2007. The impact of FCN2 polymorphisms and haplotypes on the Ficolin-2 serum levels. Scand. J. Immunol. 65, 383-392.

Munthe-Fog, L., Hummelshoj, T., Ma, Y.J., Hansen, B.E., Koch, C., Madsen, H.O., Skjodt, K., Garred, P. 2008. Characterization of a polymorphism in the coding sequence of FCN3 resulting in a Ficolin-3 (Hakata antigen) deficiency state. Mol. Immunol. 45, 2660-2666.

Ohashi, T. Erickson, H.P. 1998. Oligomeric structure and tissue distribution of ficolins from mouse, pig and human. Arch. Biochem. Biophys. 360, 223-232.

Ostergaard, J., Thiel, S., Gadjeva, M., Hansen, T.K., Rasch, R., Flyvbjerg, A. 2007. Mannosebinding lectin deficiency attenuates renal changes in a streptozotocin-induced model of type 1 diabetes in mice. Diabetologia 50, 1541-1549. 
Pan, Q., Chen, H., Wang, F., Jeza, V.T., Hou, W., Zhao, Y., Xiang, T., Zhu, Y., Endo, Y., Fujita, T., Zhang, X.L. 2012. L-ficolin binds to the glycoproteins hemagglutinin and neuraminidase and inhibits influenza A virus infection both in vitro and in vivo. J. Innate. Immun. 4, 312-324.

Pavlov, V.I., La Bonte, L.R., Baldwin, W.M., Markiewski, M.M., Lambris, J.D., Stahl, G.L. $2012 a$. Absence of mannose-binding lectin prevents hyperglycemic cardiovascular complications. Am. J. Pathol. 180, 104-112.

Pavlov, V.I., Skjoedt, M.O., Siow, T.Y., Rosbjerg, A., Garred, P., Stahl, G.L. 2012b. Endogenous and natural complement inhibitor attenuates myocardial injury and arterial thrombogenesis. Circulation 126, 2227-2235.

Ricklin, D., Hajishengallis, G., Yang, K., Lambris, J.D. 2010. Complement: a key system for immune surveillance and homeostasis. Nat. Immunol. 11, 785-797.

Rooryck, C., Diaz-Font, A., Osborn, D.P., Chabchoub, E., Hernandez-Hernandez, V., Shamseldin, H., Kenny, J., Waters, A., Jenkins, D., Kaissi, A.A., Leal, G.F., Dallapiccola, B., Carnevale, F., Bitner-Glindzicz, M., Lees, M., Hennekam, R., Stanier, P., Burns, A.J., Peeters, H., Alkuraya, F.S., Beales, P.L. 2011. Mutations in lectin complement pathway genes COLEC11 and MASP1 cause 3MC syndrome. Nat. Genet. 43, 197-203.

Ruseva, M.M., Takahashi, M., Fujita, T., Pickering, M.C. 2014. C3 dysregulation due to factor H deficiency is mannan-binding lectin-associated serine proteases (MASP)-1 and MASP-3 independent in vivo. Clin. Exp. Immunol. 176, 84-92.

Sastry, K., Herman, G.A., Day, L., Deignan, E., Bruns, G., Morton, C.C., Ezekowitz, R.A. 1989. The human mannose-binding protein gene. Exon structure reveals its evolutionary relationship to a human pulmonary surfactant gene and localization to chromosome 10. J. Exp. Med. 170, 11751189.

Sastry, R., Wang, J.S., Brown, D.C., Ezekowitz, R.A., Tauber, A.I., Sastry, K.N. 1995. Characterization of murine mannose-binding protein genes Mbl1 and Mbl2 reveals features common to other collectin genes. Mamm. Genome 6, 103-110. 
Sato, T., Endo, Y., Matsushita, M., Fujita, T. 1994. Molecular characterization of a novel serine protease involved in activation of the complement system by mannose-binding protein. Int. Immunol. 6, 665-669.

Schwaeble, W.J., Lynch, N.J., Clark, J.E., Marber, M., Samani, N.J., Ali, Y.M., Dudler, T., Parent, B., Lhotta, K., Wallis, R., Farrar, C.A., Sacks, S., Lee, H., Zhang, M., Iwaki, D., Takahashi, M., Fujita, T., Tedford, C.E., Stover, C.M. 2011. Targeting of mannan-binding lectin-associated serine protease-2 confers protection from myocardial and gastrointestinal ischemia/reperfusion injury. Proc. Natl. Acad. Sci. U. S. A 108, 7523-7528.

Schweinle, J.E., Ezekowitz, R.A., Tenner, A.J., Kuhlman, M., Joiner, K.A. 1989. Human mannosebinding protein activates the alternative complement pathway and enhances serum bactericidal activity on a mannose-rich isolate of Salmonella. J. Clin. Invest 84, 1821-1829.

Seyfarth, J., Garred, P., Madsen, H.O. 2005. The 'involution' of mannose-binding lectin. Hum. Mol. Genet. 14, 2859-2869.

Shi, L., Takahashi, K., Dundee, J., Shahroor-Karni, S., Thiel, S., Jensenius, J.C., Gad, F., Hamblin, M.R., Sastry, K.N., Ezekowitz, R.A. 2004. Mannose-binding lectin-deficient mice are susceptible to infection with Staphylococcus aureus. J. Exp. Med. 199, 1379-1390.

Sirmaci, A., Walsh, T., Akay, H., Spiliopoulos, M., Sakalar, Y.B., Hasanefendioglu-Bayrak, A., Duman, D., Farooq, A., King, M.C., Tekin, M. 2010. MASP1 mutations in patients with facial, umbilical, coccygeal, and auditory findings of Carnevale, Malpuech, OSA, and Michels syndromes. Am. J. Hum. Genet. 87, 679-686.

Skjoedt, M.O., Hummelshoj, T., Palarasah, Y., Honore, C., Koch, C., Skjodt, K., Garred, P. 2010. A novel mannose-binding lectin/ficolin-associated protein is highly expressed in heart and skeletal muscle tissues and inhibits complement activation. J. Biol. Chem. 285, 8234-8243.

Stengaard-Pedersen, K., Thiel, S., Gadjeva, M., Moller-Kristensen, M., Sorensen, R., Jensen, L.T., Sjoholm, A.G., Fugger, L., Jensenius, J.C. 2003. Inherited deficiency of mannan-binding lectinassociated serine protease 2. N. Engl. J. Med. 349, 554-560. 
Stover, C.M., Thiel, S., Thelen, M., Lynch, N.J., Vorup-Jensen, T., Jensenius, J.C., Schwaeble, W.J. 1999. Two constituents of the initiation complex of the mannan-binding lectin activation pathway of complement are encoded by a single structural gene. J. Immunol. 162, 3481-3490.

Stuart, L.M., Takahashi, K., Shi, L., Savill, J., Ezekowitz, R.A. 2005. Mannose-binding lectindeficient mice display defective apoptotic cell clearance but no autoimmune phenotype. J. Immunol. $174,3220-3226$.

Sugimoto, R., Yae, Y., Akaiwa, M., Kitajima, S., Shibata, Y., Sato, H., Hirata, J., Okochi, K., Izuhara, K., Hamasaki, N. 1998. Cloning and characterization of the Hakata antigen, a member of the ficolin/opsonin p35 lectin family. J. Biol. Chem. 273, 20721-20727.

Takahashi, K., Chang, W.C., Takahashi, M., Pavlov, V., Ishida, Y., La, B.L., Shi, L., Fujita, T., Stahl, G.L., Van Cott, E.M. 2011. Mannose-binding lectin and its associated proteases (MASPs) mediate coagulation and its deficiency is a risk factor in developing complications from infection, including disseminated intravascular coagulation. Immunobiology 216, 96-102.

Takahashi, K. Ezekowitz, R.A. 2005. The role of the mannose-binding lectin in innate immunity. Clin. Infect. Dis. 41 Suppl 7, S440-S444.

Takahashi, K., Gordon, J., Liu, H., Sastry, K.N., Epstein, J.E., Motwani, M., Laursen, I., Thiel, S., Jensenius, J.C., Carroll, M., Ezekowitz, R.A. 2002. Lack of mannose-binding lectin-A enhances survival in a mouse model of acute septic peritonitis. Microbes. Infect. 4, 773-784.

Takahashi, K., Shi, L., Gowda, L.D., Ezekowitz, R.A. 2005. Relative roles of complement factor 3 and mannose-binding lectin in host defense against infection. Infect. Immun. 73, 8188-8193.

Takahashi, M., Endo, Y., Fujita, T., Matsushita, M. 1999. A truncated form of mannose-binding lectin-associated serine protease (MASP)-2 expressed by alternative polyadenylation is a component of the lectin complement pathway. Int. Immunol. 11, 859-863.

Takahashi, M., Ishida, Y., Iwaki, D., Kanno, K., Suzuki, T., Endo, Y., Homma, Y., Fujita, T. 2010. Essential role of mannose-binding lectin-associated serine protease-1 in activation of the complement factor D. J. Exp. Med. 207, 29-37. 
Takahashi, M., Iwaki, D., Kanno, K., Ishida, Y., Xiong, J., Matsushita, M., Endo, Y., Miura, S., Ishii, N., Sugamura, K., Fujita, T. 2008. Mannose-binding lectin (MBL)-associated serine protease (MASP)-1 contributes to activation of the lectin complement pathway. J. Immunol. 180, 6132-6138.

Takahashi, M., Sekine, H., Endo, Y., Fujita, T. 2013. Comment on "Mannan-binding lectinassociated serine protease (MASP)-1 is crucial for lectin pathway activation in human serum, whereas neither MASP-1 nor MASP-3 is required for alternative pathway function". J. Immunol. 190, 2477.

Thiel, S., Vorup-Jensen, T., Stover, C.M., Schwaeble, W., Laursen, S.B., Poulsen, K., Willis, A.C., Eggleton, P., Hansen, S., Holmskov, U., Reid, K.B., Jensenius, J.C. 1997. A second serine protease associated with mannan-binding lectin that activates complement. Nature 386, 506-510.

Vorup-Jensen, T., Petersen, S.V., Hansen, A.G., Poulsen, K., Schwaeble, W., Sim, R.B., Reid, K.B., Davis, S.J., Thiel, S., Jensenius, J.C. 2000. Distinct pathways of mannan-binding lectin (MBL)- and C1-complex autoactivation revealed by reconstitution of $M B L$ with recombinant $M B L$-associated serine protease-2. J. Immunol. 165, 2093-2100.

Walsh, M.C., Bourcier, T., Takahashi, K., Shi, L., Busche, M.N., Rother, R.P., Solomon, S.D., Ezekowitz, R.A., Stahl, G.L. 2005. Mannose-binding lectin is a regulator of inflammation that accompanies myocardial ischemia and reperfusion injury. J. Immunol. 175, 541-546.

Weber-Steffens, D., Hunold, K., Kurschner, J., Martinez, S.G., Elumalai, P., Schmidt, D., Trevani, A., Runza, V.L., Mannel, D.N. 2013. Immature mouse granulocytic myeloid cells are characterized by production of ficolin-B. Mol. Immunol. 56, 488-496.

White, R.A., Dowler, L.L., Adkison, L.R., Ezekowitz, R.A., Sastry, K.N. 1994. The murine mannosebinding protein genes ( $\mathrm{Mbl} 1$ and Mbl 2) localize to chromosomes 14 and 19. Mamm. Genome 5, 807-809.

Yae, Y., Inaba, S., Sato, H., Okochi, K., Tokunaga, F., Iwanaga, S. 1991. Isolation and characterization of a thermolabile beta-2 macroglycoprotein ('thermolabile substance' or 'Hakata antigen') detected by precipitating (auto) antibody in sera of patients with systemic lupus erythematosus. Biochim. Biophys. Acta 1078, 369-376. 
Zhang, M., Takahashi, K., Alicot, E.M., Vorup-Jensen, T., Kessler, B., Thiel, S., Jensenius, J.C., Ezekowitz, R.A., Moore, F.D., Carroll, M.C. 2006. Activation of the lectin pathway by natural IgM in a model of ischemia/reperfusion injury. J. Immunol. 177, 4727-4734.

Table 1

Lectin pathway recognition molecule knockout mice

\begin{tabular}{llll}
\hline Gene knockout & Mutant allele & chromosome & Targeted exon(s) \\
\hline Mbl-a & Mbl1 $^{\text {tmlKata }}$ & 14 & 5 \\
Mbl-c & Mbl2 $^{\text {tm1Kata }}$ & 19 & 6 \\
Fcna & Fcna $^{\text {tm1Tefu }}$ & 2 & Promotor $+1-3$ \\
Fcnb & Fcnb $^{\text {tm1Yend }}$ & 2 & Promotor $+1-4$ \\
\hline
\end{tabular}


Table 2

Phenotypes of mice deficient in lectin pathway recognition molecules

\begin{tabular}{|c|c|c|c|}
\hline $\begin{array}{l}\text { Knockout } \\
\text { mouse }\end{array}$ & Experimental model & Phenotype & Reference \\
\hline MBL-A & $\begin{array}{l}\text { Cecal ligation and puncture } \\
\text { model of acute septic } \\
\text { peritonitis }\end{array}$ & $\begin{array}{l}\uparrow \text { survival compared to } \mathrm{C} 3 \mathrm{KO} \text { and WT mice } \\
\downarrow \mathrm{TNF} \alpha \text { and IL-6 }\end{array}$ & (Takahashi et al., 2002) \\
\hline MBL null & S.aureus infection & $\downarrow$ survival by i.v. inoculation & (Shi et al., 2004) \\
\hline MBL null & - & $\begin{array}{l}\text { Defective apoptotic cell clearance, but no } \\
\text { autoimmune phenotype }\end{array}$ & (Stuart et al., 2005) \\
\hline MBL null & Influenza A virus infection & $\begin{array}{l}\downarrow \text { weight loss } \\
\downarrow \text { lung inflammation and cell infiltration } \\
\downarrow \text { proinflammatory cytokines and chemokines }\end{array}$ & (Ling et al., 2012) \\
\hline MBL null & S.aureus infection & $\downarrow$ proinflammatory cytokines and chemokines & (Ip et al., 2008) \\
\hline MBLxC3 & S.aureus infection & $\downarrow$ survival compared to $\mathrm{C} 3 \mathrm{KO}$ mice & (Takahashi et al., 2005) \\
\hline MBL null & P. aeruginosa infection & $\uparrow$ susceptibility following burn injury & $\begin{array}{l}\text { (Moller-Kristensen et } \\
\text { al., 2006) }\end{array}$ \\
\hline MBL null & $\begin{array}{l}\text { Herpes simplex virus- } 2 \\
\text { infection }\end{array}$ & $\uparrow$ susceptibility & (Gadjeva et al., 2004) \\
\hline MBL null & C. albicans infection & $\uparrow$ susceptibility & (Held et al., 2008) \\
\hline MBL null & Influenza A virus infection & $\uparrow$ viral titers in the lungs & (Chang et al., 2010) \\
\hline MBL null & Kidney I/R & $\begin{array}{l}\downarrow \text { kidney damage } \\
\downarrow \text { renal complement deposition }\end{array}$ & $\begin{array}{l}\text { (Moller-Kristensen et } \\
\text { al., 2005) }\end{array}$ \\
\hline MBL null & Gastrointestinal I/R & $\begin{array}{l}\downarrow \text { intestinal injury } \\
\downarrow \text { intestinal neutrophil infiltration } \\
\downarrow \text { secondary liver injury }\end{array}$ & (Hart et al., 2005) \\
\hline sIgM/MBL & Gastrointestinal I/R & $\begin{array}{l}\downarrow \text { serum ALT levels and intestinal C3 deposition } \\
\text { when reconstituted with MBL KO plasma } \\
\text { compared to reconstitution with WT plasma }\end{array}$ & $\begin{array}{l}\text { (McMullen et al., } \\
\text { 2006) }\end{array}$ \\
\hline $\mathrm{sIgM} / \mathrm{MBL}$ & Myocardial I/R & $\begin{array}{l}\downarrow \text { left ventricular function, leakage of troponin I, } \\
\text { myocardial inflammation and C3 deposition when } \\
\text { reconstituted with MBL KO plasma compared to } \\
\text { reconstitution with WT plasma }\end{array}$ & (Busche et al., 2009) \\
\hline MBL null & Brain I/R & $\downarrow$ infarctions, C3 deposition and neutrophil & (Cervera et al., 2010) \\
\hline
\end{tabular}


infiltration in the brain

个functional outcome

MBL null $\quad \mathrm{FeCl}_{3}$-induced thrombogenesis

MBL null Brain I/R

$\mathrm{FcnA}$

S. pneumonia infection

FenB

$\mathrm{FcnA} / \mathrm{B}$

FcnA Influenza A virus infection

$\uparrow$ susceptibility

FenA M.tuberculosis infection
No decrease in blood flow

$\downarrow$ thrombus formation

Improved cerebral blood flow

$\downarrow$ infarct volumes, neurological defects and deposition of fibrinogen in blood vessels of ischemic tissue

$\downarrow$ survival

(Endo et al., 2012)
(Pan et al., 2012)

(Luo et al., 2013)

$\downarrow$ serum levels of TNF-alpha and IL-17 at $3 \mathrm{~h}$ after LPS injection 
Figure 1

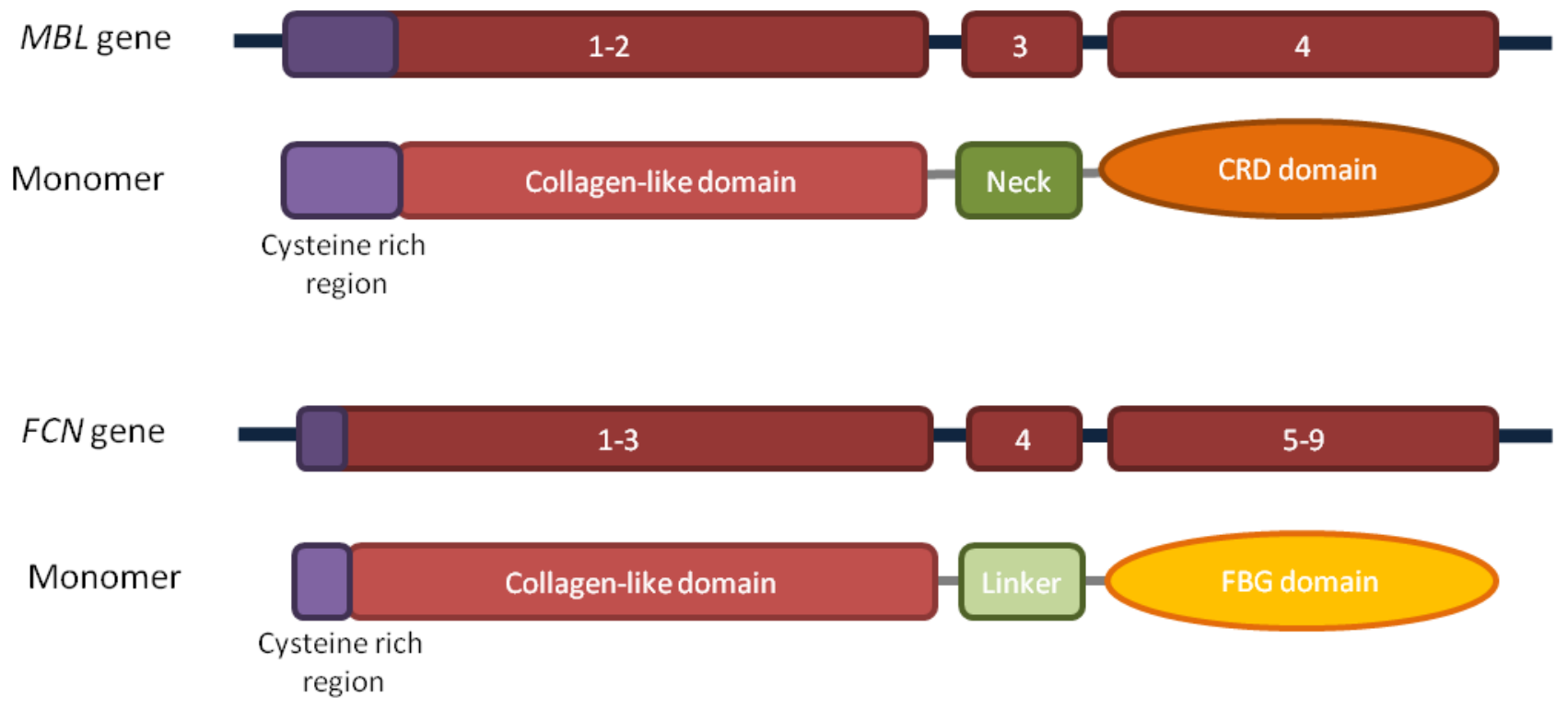


Figure 2

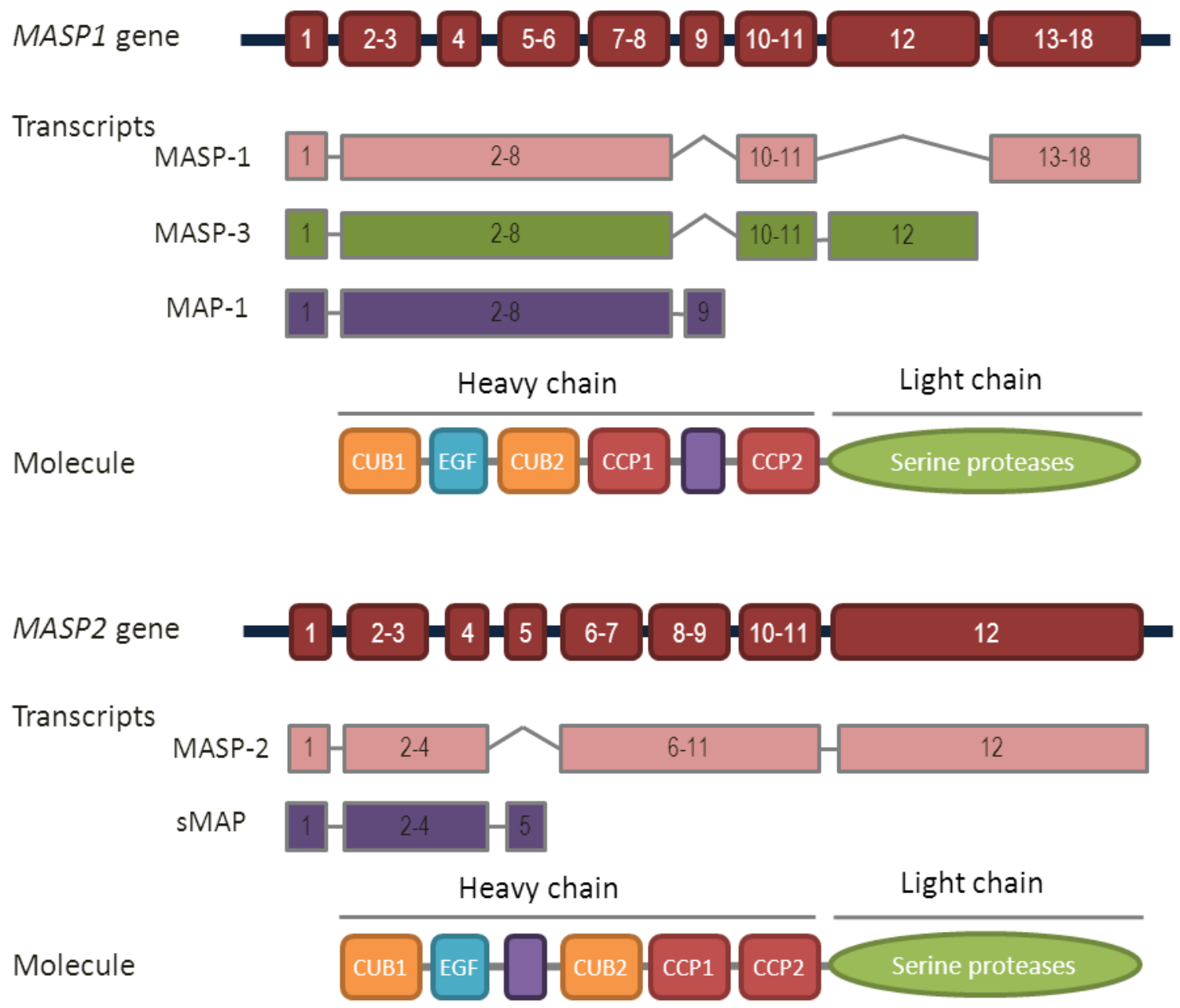


Figure 3
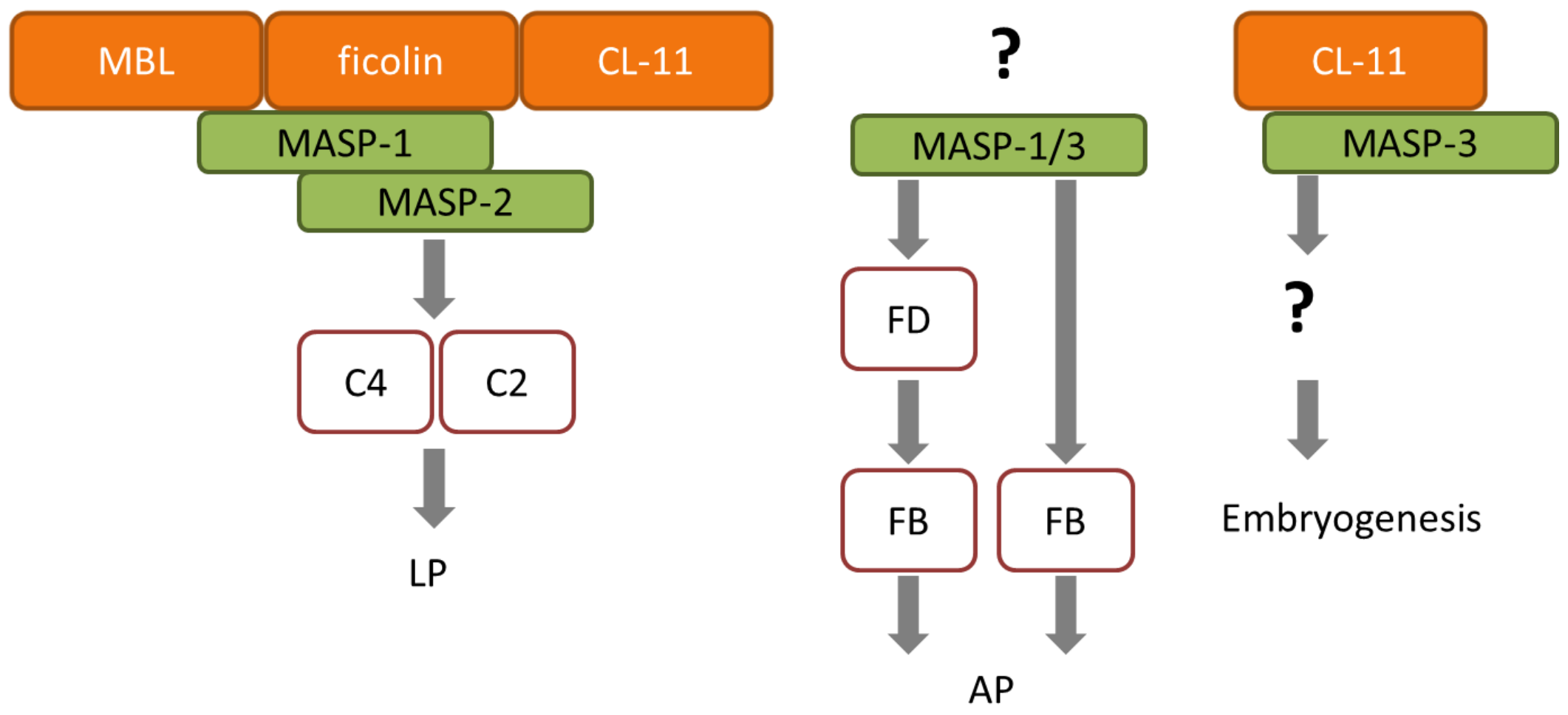